Discussion Paper 139

Institute for Empirical Macroeconomics

Federal Reserve Bank of Minneapolis

90 Hennepin Avenue

Minneapolis, Minnesota 55480-0291

October 2001

\title{
Capital Accumulation in a Model of Growth and Creative Destruction
}

\author{
Klaus Wälde \\ University of Dresden
}

\begin{abstract}
Capital accumulation and creative destruction is modeled together with risk-averse households. The novel aspect—risk-averse households-allows to use well-known models not only for analyzing long-run growth as in the literature but also short-run fluctuations. The model remains analytically tractable due to a very convenient property of the household's investment decision in this stochastic continuous-time setup.
\end{abstract}

*I thank seminar participants at CES Munich, Louvain-la-Neuve, the University of Amsterdam and the Federal Reserve Bank of Minneapolis for useful discussions and comments and especially Pat Kehoe, Tim Kehoe and Paul Segerstrom for helpful suggestions and stimulating discussions. The views expressed herein are those of the author and not necessarily those of the Federal Reserve Bank of Minneapolis or the Federal Reserve System. 


\title{
Capital accumulation in a model of growth and creative destruction
}

\author{
Klaus Wälde ${ }^{1}$, Department of Economics \\ University of Dresden, 01062 Dresden, Germany \\ www.waelde.com, klaus@waelde.com \\ Phone + 49.351.463 - 2172, Fax + 49.351.463 - 7736 \\ September 2001
}

\begin{abstract}
Capital accumulation and creative destruction is modeled together with risk-averse households. The novel aspect - risk-averse households - allows to use well-known models not only for analyzing long-run growth as in the literature but also short-run fluctuations. The model remains analytically tractable due to a very convenient property of the household's investment decision in this stochastic continuous-time setup.
\end{abstract}

Keywords: Creative destruction, Risk averse households, Capital accumulation, Endogenous fluctuations and growth

JEL Classification: E32 Business Fluctuations, Cycles; O41 One, Two, and Multisector Growth Models; O31 Innovation and Invention: Processes and Incentives

\section{Introduction}

Aghion and Howitt (1992) have presented a very influential model of endogenous growth. Long-run growth results from R\&D for improved intermediate goods where each new vintage of intermediate goods yields a higher total factor productivity. While the original presentation of the model did not take capital accumulation into consideration, various more recent contributions (Aghion and Howitt, 1998; Howitt and Aghion, 1998, Howitt, 1999) combined capital accumulation with R\&D.

\footnotetext{
${ }^{1}$ I thank seminar participants at CES Munich, Louvain-la-Neuve, the University of Amsterdam and the Federal Reserve Bank of Minnesota for useful discussions and comments and especially Pat Kehoe, Tim Kehoe and Paul Segerstrom for helpful suggestions and stimulating discussions.
} 
These contributions share the feature of risk-neutral agents. Wälde (1999a) has shown that introducing risk-averse households into the Aghion and Howitt (1992) model substantially alters equilibrium properties. Three out of four market failures disappear and a new market failure resulting from a complementarity in financing $\mathrm{R} \& \mathrm{D}$ is identified. It is the objective of the present paper to show that extending also Aghion and Howitt's (1998), Howitt and Aghion's (1998) and Howitt's (1999) model for risk-averse households considerably broadens the range of phenomena to which their model can be applied. Such an extension allows to understand not only long-run growth but also short-run fluctuations. Aghion and Howitt's basic setup implies therefore much richer predictions once the assumption of risk-neutrality is relaxed.

The next section presents a model that contains the central features of Aghion and Howitt's setup, notably an R\&D sector whose probability of success (arrival rate) depends on the amount of resources allocated to R\&D. In addition, capital accumulation and the consumption and investment decision of risk-averse households are modeled explicitly.

The economy we present produces one good that can be used for consumption, for capital accumulation and as an input for risky R\&D. This good employs capital and labour. Risk-averse households can use their savings for financing capital accumulation and $R \& D$. As this investment decision is based on (expected) returns, the amount of resources allocated to capital accumulation will be high when returns to capital accumulation are high relatively to expected returns to $R \& D$.

With high capital returns, capital accumulation will be fast. When returns to capital accumulation have fallen (due to decreasing returns to capital), capital accumulation will be slower - just as on the saddle path of a standard Ramsey growth model. When capital returns are sufficiently low, research for new technologies will be financed. Once research is successful, a new technology is available and returns to capital accumulation will again be high. The discrete increase in total factor productivity due to new technologies combined with gradual capital accumulation allows to jointly understand short-run fluctuations and long-run growth. ${ }^{2}$

Two features of the model presented here that differ from Aghion and Howitt's setup are worth being emphasized: First, gradual capital accumulation can be studied only with risk-averse households. Hence without risk-aversion, short-run fluctuations (of the type presented here) can not be understood. Second, some features of Aghion and Howitt's setup, which are not essential for the argument we want to make here, are not taken into con-

\footnotetext{
${ }^{2}$ Some equilibrium properties of the present model resemble the findings of Bental and Peled (1996) and Matsuyama (1999), who use a discrete-time framework.
} 
sideration. Most importantly, the present model does not have any imperfect competition features. Modeling an economy that is perfectly competitive in all sectors (and therefore has no monopolist in the intermediate good sector) makes the model very tractable. Incentives for $R \& D$ are nevertheless present in a decentralized economy as the outcome of R\&D is assumed to consist not only in a blueprint but also in a prototype of the new units of production. As will become clear below, the qualitative properties of the present model should be identical to qualitative properties of a model with a monopolist in the intermediate goods sector.

\section{The model}

\subsection{Technologies}

Technological progress is labour augmenting and embodied in capital. A capital good $K_{j}$ of vintage $j$ allows workers to produce with a labour productivity of $A^{j}$. Hence, a more modern vintage $j+1$ implies a labour productivity that is $A$ times higher than labour productivity of vintage $j$. The production function corresponding to this capital good reads

$$
Y_{j}=K_{j}^{\alpha}\left(A^{j} L_{j}\right)^{1-\alpha} .
$$

The amount of labour allocated to this capital good is denoted by $L_{j}, 0<$ $\alpha<1$ is the output elasticity of capital. The sum of labour employment $L_{j}$ per vintage equals aggregate constant labour supply $L$,

$$
\Sigma_{j=0}^{q} L_{j}=L,
$$

where $q$ is the most advanced vintage currently available.

Independently of which vintage is used, the same type of output is produced. Aggregate production therefore equals

$$
Y=\Sigma_{j=0}^{q} Y_{j}
$$

Aggregate output is used for producing consumption goods $C$, investment goods $I$ and it is used as an input $R$ for doing R\&D,

$$
C+I+R=Y \text {. }
$$

The objective of R\&D is to develop capital goods that yield a higher labour productivity than existing capital goods. R\&D is an uncertain activity which is modeled by the Poisson process $q$. The probability per unit of time 
$d t$ of successful R\&D is given by $\lambda d t$, where $\lambda$ is the arrival rate of the process $q$. This arrival rate is an increasing function of the amount of resources $R$ used for R\&D,

$$
\lambda=R / D(q) .
$$

The parameter $D(q)$, a fundamental of the model, captures differences in sector input requirements between $R \& D$ and the other sectors. It is an increasing function of the currently most advanced vintage $q$, as will be discussed later. It will basically be used to remove the well-known scale effect (Backus, Kehoe and Kehoe, 1992; Jones, 1995; Segerstrom, 1998; Young, 1998; Howitt, 1999) in the present model.

When R\&D is successful, a first prototype of a production unit that yields a labour productivity of $A^{q+1}$ becomes available. Let the size of this first machine be given by $\kappa_{q+1} \cdot{ }^{3}$ It might appear unusual that research actually leads to a first production unit. Usually, output of successful research is modeled as a blueprint. It should not be to difficult to imagine, however, that at the end of some research project, engineers have actually developed a first machine that implies this higher labour productivity. With this assumption, there are incentives to finance $R \& D$ in a decentralized economy even though all sectors produce under perfect competition: Those who have financed R\&D obtain the production unit $\kappa_{q+1}$, whose capital rewards balance R\&D costs. Hence, no profits by a monopolist are required. ${ }^{4}$ As a second effect of successful R\&D, the economy can accumulate capital that yields this higher labour productivity. This is a positive externality. ${ }^{5}$

Each vintage of capital is subject to depreciation at the constant rate $\delta$. If more investment is allocated to vintage $j$ than capital is lost due to depreciation, the capital stock of this vintage increases in a deterministic way,

$$
d K_{j}=\left(I_{j}-\delta K_{j}\right) d t, \quad j=1 \ldots q .
$$

When research is successful, the capital stock of the next vintage $q+1$ increases discretely by the size $\kappa_{q+1}$ of the first new machine of vintage $q+1$,

$$
d K_{q+1}=\kappa_{q+1} d q .
$$

\footnotetext{
${ }^{3}$ The size can differ for different vintages and we will later assume that $\kappa_{q}$ increases in $q$.

${ }^{4}$ With a monopolist and capital, agents could hold capital and shares in the monopolist. This would require asset pricing which would make the model intractable when transitional dynamics are to be analyzed.

${ }^{5}$ There is an interesting link to the Coase theorem as it was recently amended by Dixit and Olson (2000): When bundling a collective good (the new technology) with a private good (the new machine), the collective good will be provided.
} 
Afterwards, (5) would apply to vintages $j=1 \ldots q+1 .^{6}$

Before describing households in this economy, we now derive some straightforward equilibrium considerations that both simplify the presentation of the production side and, more importantly, the derivation of the budget constraint of households in the next section.

Allowing labour to the mobile across vintages $j=1 \ldots q$ such that wage rates equalise, total output of the economy can be represented by a simple Cobb-Douglas production function (cf. appendix 6.1)

$$
Y=K^{\alpha} L^{1-\alpha} .
$$

Vintage specific capital stocks have been aggregated to an aggregate capital index $K$,

$$
K=K_{0}+B K_{1}+\ldots+B^{q} K_{q}=\Sigma_{j=0}^{q} B^{j} K_{j}, \quad B=A^{\frac{1-\alpha}{\alpha}} .
$$

This index can be considered to be a quality-adjusted measure of the aggregate capital stock, where $B^{j}$ captures the quality of capital of vintage $j$. The value marginal productivity of a vintage $j$ is then given by

$$
w_{j}=p_{C} \frac{\partial Y}{\partial K} B^{j},
$$

where $p_{C}$ is the price of the consumption good.

The evolution of this aggregate capital index $K$ follows from (5) and (6). Given that the price of an investment good does not depend on where this investment good is used, that depreciation is the same for all investment goods and given that value marginal productivities (9) are highest for the most advanced vintage, investment takes place only in the currently most advanced vintage $q$,

$$
I_{j}=\left\{\begin{array}{cc}
0 & \forall j<q \\
I & j=q
\end{array} .\right.
$$

Hence,

$$
\begin{aligned}
d K & =\left(-\delta K_{0}-B \delta K_{1}-\ldots-B^{q-1} \delta K_{q-1}+B^{q}\left[I_{q}-\delta K_{q}\right]\right) d t+B^{q+1} \kappa_{q+1} d q \\
& =\left(B^{q} I-\delta K\right) d t+B^{q+1} \kappa_{q+1} d q .
\end{aligned}
$$

Concerning prices in this economy, technologies presented above imply

$$
p_{Y}=p_{C}=p_{I}=p_{R}
$$

\footnotetext{
${ }^{6}$ Formally, this equation is a stochastic differential equation driven by the Poisson process $q$. The increment $d q$ of this process can either be 0 or 1 . Successful R\&D means $d q=1$. For an introduction cf. e.g. Dixit and Pindyck (1994).
} 
Good $Y$ will be chosen as numeraire. Prices $p_{Y}, p_{C}, p_{I}, p_{R}$ will therefore be constant throughout the paper; we will nevertheless use them at various places (and not normalize to unity) as this makes some derivations more transparent. As long as investment is positive, the price $v_{q}$ of an installed unit of the most recent vintage of capital equals the price of an investment good, $v_{q}=p_{I}$. As different vintages are perfect substitutes in production (8), prices of different vintages are linked to each other by

$$
p_{I}=v_{q}=B^{q-j} v_{j}, \quad \forall j=0 \ldots q .
$$

Further, the price $p_{K}$ of one efficiency unit of capital (which corresponds to one unit of capital of vintage 0 ) is a decreasing function of the most advanced vintage $q$,

$$
p_{K}=B^{-q} p_{I} .
$$

This also reflects the term $B^{q}$ in the capital accumulation equation (10).

The pricing relationship (12) reveals a creative destruction mechanism in the model, despite the absence of aggressive competition between firms (as e.g. in the original Aghion and Howitt model where the intermediate firm is always a monopolist). When a new vintage is found, i.e. when $q$ increases by one, the price of older vintages relative to the consumption good fall as $v_{j} / p_{C}=B^{-(q-j)}$. Capital owners therefore experience a certain reduction in their wealth.

\subsection{Households}

There is a discrete finite number of households in this economy. Each household is sufficiently small to neglect the effects of own behavior on aggregate variables. Households maximize expected utility $U(t)$ given by the sum of instantaneous utility $u($.$) resulting from consumption flows c(\tau)$, discounted at the time preference rate $\rho$,

$$
U(t)=E \int_{t}^{\infty} e^{-\rho[\tau-t]} u(c(\tau)) d \tau,
$$

where the instantaneous utility function $u($.$) is characterized by constant$ relative risk aversion,

$$
u(c(\tau))=\frac{c(\tau)^{1-\sigma}-1}{1-\sigma} .
$$

For saving purposes, households can buy capital and finance R\&D. When they buy capital, their wealth $a$ increases in a deterministic and continuous 
way. This increase depends on the difference between capital plus labour income $r a+w$ minus expenditure $i$ for $\mathrm{R} \& \mathrm{D}$ and expenditure $p_{C} c$ for consumption. When financing $\mathrm{R} \& \mathrm{D}$, i.e. when $i$ is positive, successful research changes their wealth in a discrete way. A household receives the same share of the value of the successful research project that it has contributed to financing this project. When total investment into research is given by $J$, the household receives the share $i / J .^{7}$ The value of the successful research project depends on the price $v_{q+1}$ of the capital good and the "size" $\kappa_{q+1}$ of the prototype.

Summarizing, the budget constraint (16) is a stochastic differential equation, where the deterministic part (.) $d t$ stems from buying capital and the stochastic part (.) $d q$ captures the effects of financing R\&D. As in (6), when $\mathrm{R} \& \mathrm{D}$ is successful, the increment $d q$ of the Poisson process $q$ underlying R\&D equals unity, otherwise, $d q=0$. A negative effect of successful research stems from the devaluation of capital, as discussed in relation to the pricing equation (12). As the relative price (13) of an efficiency unit of capital falls when a new vintage is discovered, households experience a loss in the value of their assets relative to the consumption good price. The share of assets that is "lost" due to this devaluation is denoted by $s$. Hence,

$$
d a=\left(r a+w-i-p_{C} c\right) d t+\left(v_{q+1} \kappa_{q+1} \frac{i}{J}-s a\right) d q
$$

where

$$
s=\frac{B-1}{B}
$$

and the interest-rate is given by

$$
r=B^{q} \frac{\partial Y}{\partial K}-\delta
$$

This budget constraint is formally derived in the appendix $6.2 .{ }^{8}$

\section{Solving the model}

This section shows that the economy can be analyzed almost as easily as a standard textbook growth model. All optimality and equilibrium conditions

\footnotetext{
${ }^{7}$ This sharing rule introduces an externality in this economy. Individuals tend to invest too much, as shown (in a different setup) in Wälde (1999a).

${ }^{8}$ To check internal consistency of a model, it is useful to aggregate individual budget constraints (16) and see whether they sum up to the economy wide capital accumulation constraint (10). This is shown in appendix 6.3 .
} 
will be expressed in terms of aggregate consumption $C$ and the capital stock $K$. The behavior of the economy will then be summarized in the next section an almost standard phase diagram.

\subsection{Investment decisions of households}

Households maximize utility (14) subject to the budget constraint (16) by choosing investment $i$ into R\&D and the consumption level $c$. Optimal investment follows a bang-bang investment rule saying that either no savings are used for R\&D at all or all savings a used for R\&D. Formally (cf. appendix 6.4 or Wälde, 1999b),

$$
i=\left\{\begin{array}{c}
0 \\
r a+w-p_{C} c
\end{array}\right\} \Longleftrightarrow r-\rho-\lambda[1-(1-s) \Omega]\left\{\begin{array}{l}
> \\
=
\end{array}\right\} 0 .
$$

where

$$
\Omega=\frac{u^{\prime}(\tilde{c})}{u^{\prime}(c)}
$$

is the ratio of marginal utility of consumption under the new technology to marginal utility of consumption under the current technology. In this paper, a tilde $(\sim)$ denotes the value of a variable immediately after successful R\&D. This rule says that $\mathrm{R} \& \mathrm{D}$ is not financed $(i=0)$ when the right hand side is positive, i.e. when returns $r$ to capital accumulation are sufficiently high. With low returns such that the right hand side is zero (as shown in Wälde (1999b) and as we will see, it cannot be negative in equilibrium), all savings net of capital depreciation will be used for financing R\&D.

This bang-bang result might be surprising but it is extremely useful for keeping the model tractable. It is the consequence of three sufficient (not necessarily necessary) conditions: (i) there is a representative consumer, so distributional aspects are not taken into consideration here, (ii) the $R \& D$ sector operates under constant returns to scale, a standard assumption that allows us to model perfect competition and (iii) the result $\kappa_{q+1}$ of a successful research project is independent of the amount of resources allocated to R\&D. More or less investment into R\&D has only an impact on the probability of success, not on its outcome $\kappa_{q+1} \cdot{ }^{9}$

It is important to note at this point that allocating all savings to $R \& D$ implies that wealth of households remains constant (as long as R\&D is not

\footnotetext{
${ }^{9}$ This bang-bang property can also be found in central planner solutions of economies of this type (Wälde, 2001). A technical condition is the continuous-time setup. Discrete-time models would have an interior solution (Wälde, 1998, ch.8).
} 
successful). This directly follows from inserting $i=r a+w-p_{C} c$ into the budget constraint (16) of households. When wealth of households is constant, aggregate wealth, i.e. the capital stock needs to remain constant as well. Hence, when all savings are allocated to $R \& D$, there is still some investment in new equipment such that depreciation is just balanced.

Looking at the expression for the interest-rate (18) shows that this is no contradiction to the allocation of all savings to R\&D. Savings are net savings, i.e. gross savings $B^{q} \frac{\partial Y}{\partial K} a+w-p_{C} c$ minus $\delta a$, losses due to depreciation. Hence, gross savings are used for keeping wealth (and thereby the capital stock) constant and for financing $\mathrm{R} \& \mathrm{D}, B^{q} \frac{\partial Y}{\partial K} a+w-p_{C} c=\delta a+i$.

From an intuitive point of view, this rule can most easily be understood by looking at the Keynes-Ramsey rule that would hold in an economy where households allocate savings both to R\&D and capital accumulation, i.e. where an interior solution for investments into $R \& D$ exists. It reads (cf. appendix 6.5)

$$
-\frac{d u^{\prime}(c)}{u^{\prime}(c)}=[r-\rho-\lambda[1-[1-s] \Omega]] d t+[1-\Omega] d q .
$$

The deterministic part of this rule is identical to the investment rule. The deterministic part says that consumption grows as long as the interest rate $r$ is sufficiently high. When the interest rate is too low, no further accumulation of assets takes place. This is a well-known relationship from standard growth models.

This helps to understand the above investment rule for the case where no interior solution for investment into R\&D exists. As long as the interest-rate is sufficiently high, only capital accumulation takes place and consumption rises. When the interest-rate has fallen to $\rho+\lambda[1-[1-s] \Omega]$, no further assets are accumulated and consumption is constant. Hence all savings go to financing R\&D.

\subsection{The regimes of the economy}

We now exploit the implications of the investment rule. When no R\&D is undertaken, the economy finds itself in a period of deterministic changes, the deterministic regime. When $\mathrm{R} \& \mathrm{D}$ is undertaken, the economy finds itself in a stochastic regime.

\subsubsection{Deterministic regime}

When all savings are allocated to capital accumulation, no research takes place and no uncertainty is present in the economy. In those "deterministic 
times", consumption follows the standard Keynes-Ramsey rule,

$$
-\frac{u^{\prime \prime}(C)}{u^{\prime}(C)} \dot{C}=r-\rho
$$

where $C$ is aggregate consumption. Capital accumulation is then also deterministic and reads from (10) and (3)

$$
\dot{K}=B^{q}(Y-C)-\delta K .
$$

\subsubsection{Stochastic regime}

By contrast, when the interest rate is sufficiently low such that the investment rule (19) advises to allocate all savings to $R \& D$, the economy finds itself on what could be called the R\&D line. This line follows from the investment rule (19) and reads (cf. appendix 6.6)

$$
B^{q} \frac{\partial Y}{\partial K}-\delta-\rho=\frac{Y-B^{-q} \delta K-C}{D(q)}\left(1-\frac{D(q)}{B \kappa_{q+1}}\right) .
$$

This line gives combinations of the aggregate capital stock and consumption where the economy is in the stochastic regime. As follows from the discussion of (19), individual consumption, individual wealth and therefore aggregate consumption and the aggregate capital stock are constant on this line. The economy is therefore in a transitory stationary equilibrium.

At some point, however, a new technology will be found and individuals adjust their saving plans. The associated jump in consumption is given by (cf. appendix 6.4),

$$
u^{\prime}(C)=\frac{\kappa_{q+1}}{D(q)} u^{\prime}(\tilde{C})
$$

\section{Cycles and growth}

This section shows how a phase diagram can be used to illustrate the equilibrium path of the economy. It also presents selected properties of time paths as predicted by the model.

\subsection{The equilibrium path}

Studying a standard phase diagram would be cumbersome as the phase diagram "grows" with each vintage. More formally, zero-motion lines are a function of the most advanced vintage $q$ and they shift outward when $q$ rises. 
We will therefore present a phase diagram where variables have been transformed according to

$$
K=\hat{K} A^{q / \alpha}, \quad C=\hat{C} A^{q}
$$

With these new productivity-adjusted variables $\hat{K}$ and $\hat{C}$, zero-motion lines are vintage-independent.

\subsubsection{Zero-motion lines}

The phase diagram consists of zero-motion lines and, in addition to standard phase diagrams, of an R\&D line. Productivity-adjusted capital and consumption follow (cf. appendix 6.7)

$$
\begin{aligned}
\frac{d}{d t} \hat{K} & =\hat{Y}-\hat{C}-\delta \hat{K}, \\
\frac{d}{d t} \hat{C} & =\frac{\hat{r}-\rho}{\sigma} \hat{C} .
\end{aligned}
$$

The zero-motion lines for consumption and capital are then

$$
\hat{C}=\hat{Y}-\delta \hat{K}, \quad \hat{r}=\rho,
$$

where

$$
\hat{Y}=\hat{K}^{\alpha} L^{1-\alpha}, \quad \hat{r}=\alpha(L / \hat{K})^{1-\alpha}-\delta .
$$

\subsubsection{The R\&D line and jumps in consumption and capital}

Transforming the R\&D line (24) yields (cf. appendix 6.7)

$$
\hat{C}=\hat{Y}-\delta \hat{K}-\phi \frac{\hat{r}-\delta-\rho}{1-\frac{\phi}{A^{1 / \alpha} \hat{\kappa}}} .
$$

For this transformation, we assumed

$$
D(q)=\phi A^{q}, \quad \text { and } \kappa_{q+1}=A^{q+1} \hat{\kappa},
$$

where $\phi$ is a positive parameter that reflects relative productivity of investment vs. R\&D. This derivation assumed also

$$
1-\frac{D(q)}{B \kappa_{q+1}}=1-\frac{\phi}{A^{1 / \alpha} \hat{\kappa}}>0 .
$$


Both the parameter $\phi$ and this parameter restriction will be discussed when drawing the phase diagram.

The first assumption in (31) is by now standard in models of economic growth. It implies by the resource constraint (3) of the economy that more resources are required to increase labour productivity with a "probability" $\lambda$ from $q$ to $q+1$ than with the same $\lambda$ from $q-1$ to $q$. When $q$ machines with each one providing higher productivity have already been developed, it is harder to find new and more productive ones. ${ }^{10}$

Without this assumption, the economy would be characterized by the scale effect: The larger the economy, the faster it grows (which is empirically disputed, cf. e.g. Jones 1995 or Backus, Kehoe and Kehoe, 1992). This scale effect has been solved in many ways (Segerstrom, 1998; Young, 1998; Howitt, 1999), of which the approach chosen here (close to Segerstrom, 1998) appears to be the simplest one from a modelling perspective.

The second assumption implies that the size of new machines is such that total factor productivity of this new machine (compare the technology (1)) is $A$ times higher than total factor productivity with the previous vintage. Both assumptions together yield a productivity-adjusted R\&D line (30) that is an invariant line in the productivity-adjusted phase diagram.

The consumption jump condition (25) reads with (15) and (31)

$$
C^{-\sigma}=\frac{A \hat{\kappa}}{\phi} \tilde{C}^{-\sigma} \Leftrightarrow \tilde{C}=\left(\frac{A \hat{\kappa}}{\phi}\right)^{1 / \sigma} C
$$

for actual consumption and

$$
\hat{\tilde{C}}=A^{-1}\left(\frac{A \hat{\kappa}}{\phi}\right)^{1 / \sigma} \hat{C}
$$

for productivity-adjusted consumption.

The capital stock increases due to successful research according to (10) by $\tilde{K}-K=B^{q+1} \kappa_{q+1}$. Productivity-adjusted capital changes following (26) and (31) are then given by

$$
\hat{\tilde{K}}=\hat{K} / A^{1 / \alpha}+\hat{\kappa}
$$

\footnotetext{
${ }^{10}$ Segerstrom (2001) provides convincing data on R\&D expenditures by Intel who supports this (and his) view.
} 


\subsubsection{Equilibrium}

Let us now plot the phase diagram that will help to understand what an equilibrium in this economy is.

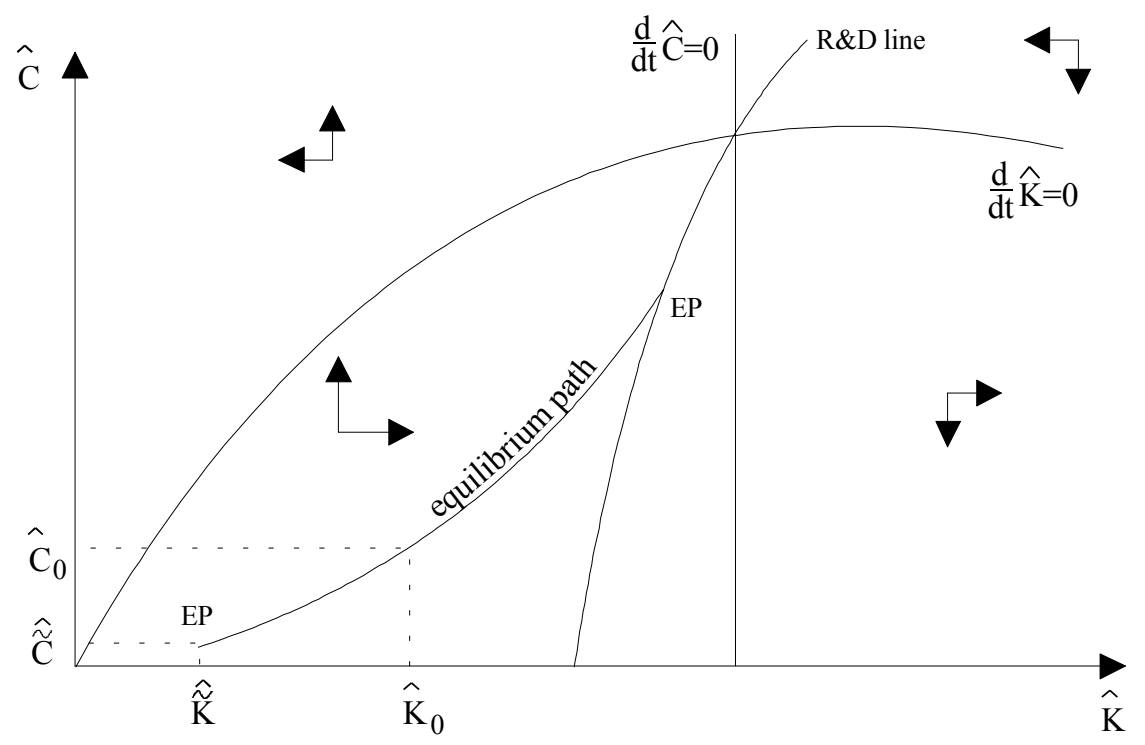

Figure 1: Long-run growth and short-run cycles

This figure plots $\hat{K}$ on the horizontal and $\hat{C}$ on the vertical axis. Zeromotion lines have the usual shape and laws of motion indicated by arrows are identical to standard Ramsey growth models as well. The R\&D line is upward sloping and crosses the steady state. The slope of the R\&D line crucially depends on $\phi$, the parameter that captures relative productivity of the $\mathrm{R} \& \mathrm{D}$ sector vs. the investment good sector. A high $\phi$ means high productivity in the investment goods sector relative to the research sector (compare (31) and (4) with the resource constraint (3)). The higher $\phi$, the further the R\&D line (30) moves to the right. Ceteris paribus, this means longer capital accumulation before $R \& D$ starts.

The R\&D line lies below the zero-motion line for capital because of the parameter restriction (32). If $1-\phi /\left(A^{1 / \alpha} \hat{\kappa}\right)=0$, the $\mathrm{R} \& \mathrm{D}$ line would coincide with the zero-motion line for consumption. This can most easily be seen from the expression for the R\&D line in (24). If $1-\phi /\left(A^{1 / \alpha} \hat{\kappa}\right)>0$, the $\mathrm{R} \& \mathrm{D}$ line would lie above the zero-motion line for capital. ${ }^{11}$

\footnotetext{
${ }^{11}$ In the present paper, we restrict attention to the case in $(32)$. When the R\&D line coincides with the zero-motion line for consumption, identical results should hold. The implications of an R\&D line lying above the zero motion line for capital are still to be worked out.
} 
Equations (27), (28), (30), (33) and (34) jointly determine the evolution of productivity-adjusted capital and consumption in this economy. An equilibrium is a path $E P-E P$ as drawn in the phase diagram, starting at a point $\left(\hat{K}_{0}, \hat{C}_{0}\right)$, following laws of motion $(27)$ and (28), ending on the R\&D line (30), jumping according to $(33)$ and $(34)$ to $(\hat{\tilde{K}}, \hat{\tilde{C}})$ ending up after having followed again laws of motion $(27)$ and $(28)$ at $\left(\hat{K}_{0}, \hat{C}_{0}\right) \cdot{ }^{12,13}$

\subsection{Properties of the equilibrium path}

This section will present properties of the equilibrium path of this economy. It studies both the long-run and the short-run predictions of the model. While it would be extremely interesting to calibrate this model and derive quantitative predictions, this is left for future work. ${ }^{14}$

\subsubsection{Short-run fluctuations}

This economy is characterized by long-run growth with short-run fluctuations. The evolution of the economy can nicely be summarized using the above phase diagram. The subsequent discussion refers to actual quantities (like $K$ and $C$ rather than productivity-adjusted variables $\hat{K}$ and $\hat{C}$ ), assuming the economy is in equilibrium.

Let the economy start with a capital stock $K_{0}$ and let it choose a consumption level such that it is on the equilibrium path $E P-E P$. As returns to capital are sufficiently high, no one wants to finance research for new technologies. The economy therefore accumulates more capital of the currently most advanced vintage and approaches the $\mathrm{R} \& \mathrm{D}$ line. Consumption rises and returns to capital fall.

After some finite length of time, the economy hits the R\&D line (at the upper $E P$ ). Investors realize that capital rewards have fallen so much that they are now indifferent between accumulating capital and financing

\footnotetext{
${ }^{12}$ We assume in what follows existence of equilibrium. A proof could follow the lines in Wälde (2001). A detailed analysis of necessary and sufficient conditions is currently being undertaken.

${ }^{13}$ In equilibrium, the interest rate is always larger or equal to $\rho+\lambda[1-(1-s) \Omega]$, as argued in (19). The interest rate would be smaller than this expression only if the economy were below the R\&D line.

${ }^{14}$ As the objective of a theoretical model is to present an argument as easily as possible, certain predictions especially on cyclical and counter-cyclical behavior are extreme. In work in progress (in a discrete time version of the present model), the author shows that these extreme predictions can be weakend which makes the discrete-time version more suitable for calibration.
} 
research for a new technology. Resources that were used an instant before for producing new capital equipment are now used for searching for a better type of capital. As long as research is not successful, the economy remains on the R\&D line at this point EP. Some new capital goods continue to be produced, just to compensate depreciation. Hence, the aggregate capital stock is constant.

Once a new technology is found, the economy is hit by an endogenous technology shock. Its capital stock increases in a discrete way by the size of the new machine $\kappa_{q+1}$ as shown in (10) and consumption jumps according to the consumption jump condition (25). The capital stock $K$ unambiguously increases, consumption might rise or fall.

After these discrete changes in aggregate capital and consumption, the economy starts accumulating capital again in a smooth way. It now accumulates capital of the new vintage. With this new vintage, the consumption level is on average $A$ times higher than one vintage before. This increase in labour productivity implies positive long-run growth. Moving up the equilibrium path towards the R\&D line implies non-constant growth rates.

Short run properties of this model are presented in the following figures.
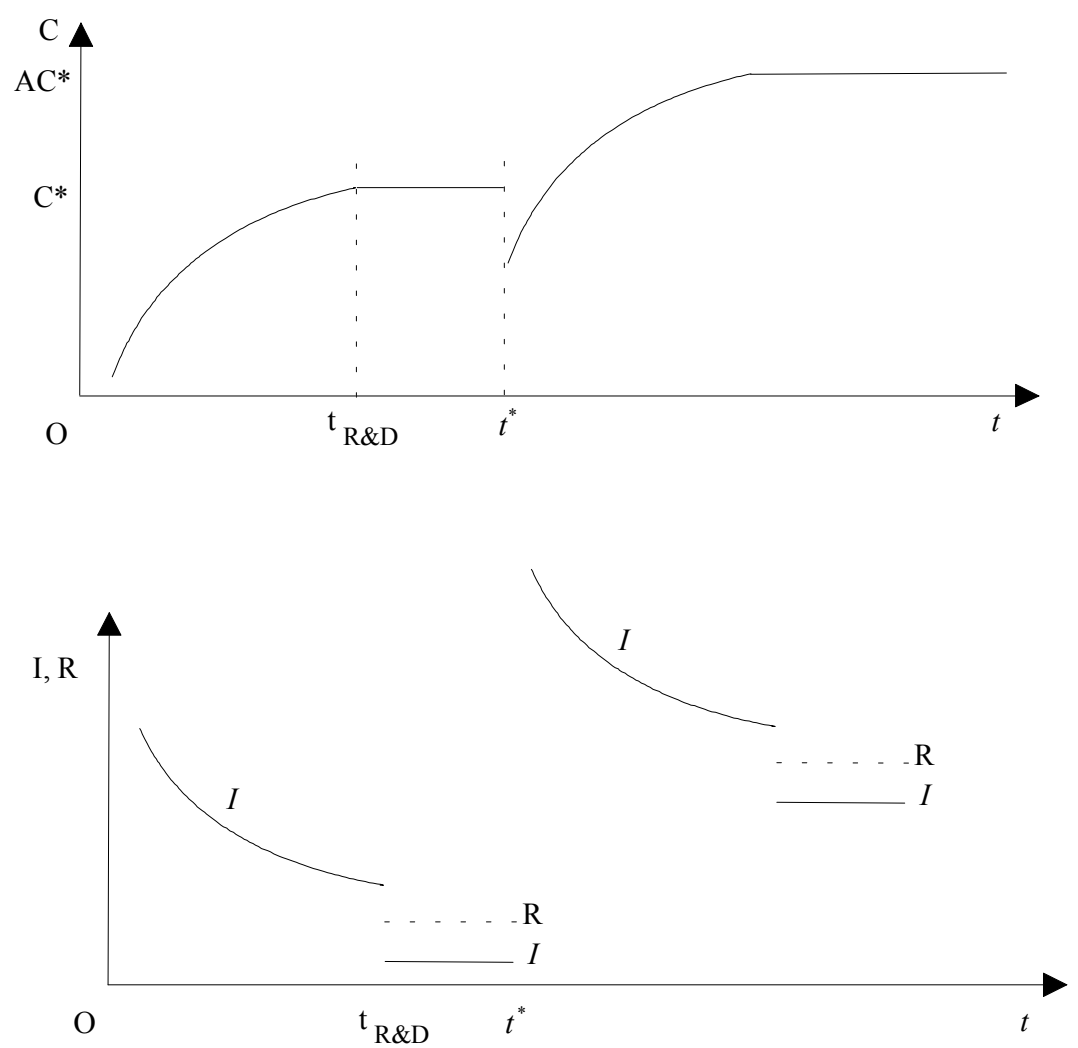

Aggregate consumption plotted in the upper figure rises over time until 
the economy hits the $\mathrm{R} \& \mathrm{D}$ line at $t_{R \& D}$. From then on, research is undertaken and consumption is constant. At some point in time $t^{*}$, research is successful. The length between $t_{R \& D}$ and $t^{*}$ is indeterminate, while the expected length is given by $\lambda^{-1}$. Consumption rises or falls after successful research. Inserting assumptions (31) into (25) yields

$$
u^{\prime}(C)=\frac{A \hat{\kappa}}{\phi} u^{\prime}(\tilde{C})
$$

This implies

$$
\tilde{C} \gtrless C \Leftrightarrow \frac{A \hat{\kappa}}{\phi} \gtrless 1
$$

As by the assumption (32) we made in deriving the $R \& D$ line, $\frac{A^{1 / \alpha} \hat{\kappa}}{\phi}>1$, $\frac{A \hat{\kappa}}{\phi}$ can be larger or smaller than unity, given that $A$ is larger than unity by definition and $0<\alpha<1$. The increase in consumption from a given point of one cycle to the same point of the next cycle is known, however: Denoting the consumption level on, say, the $\mathrm{R} \& \mathrm{D}$ line by $C^{*}$, consumption on the $\mathrm{R} \& \mathrm{D}$ line in the next cycle is $A$ times higher at $A C^{*}$. This immediately follows from the transformation (26) and the fact that in equilibrium productivitycorrected consumption $\hat{C}$ is at the same level independently of the currently most advanced vintage $q$.

Output and capital follow qualitatively identical paths to consumption. In contrast to consumption, output and capital definitely increase after successful R\&D. Output also increases from one cycle to the next one by the factor $A$. The physical capital stock increases by $A^{1 / \alpha}$, which also follows from (26) and vintage independent $\hat{K}$. Measuring the capital stock in terms of the consumption good, however, shows that it increases by $A$ as well (cf. next section on long-run growth). The growth rate of output relative to capital is given by the standard expression $\dot{Y} / Y=\alpha \dot{K} / K$. The growth rate of output relative to consumption depends on whether consumption drops or rises after successful $R \& D$. When it drops, consumption grows faster than output (as at the end of a cycle both have increased by the same factor $A$ ). If consumption rises more than output, output grows faster than consumption.

Investment decreases over time, as does the interest rate, while resources $R$ are allocated to R\&D only at the end of a cycle. This is shown in the lower part of the figure. Resources $R$ allocated to $R \& D$ in the stochastic regime are lower than resources used for investment $I$ an instant before R\&D starts: Aggregate output $Y$ does not jump when the economy hits the R\&D line, simply because the capital stock does not jump at this point. As consumption remains constant as well, the amount of resources for investment and R\&D in 
the stochastic regime are just as high as an instant before the economy hits the R\&D line. This follows from the resource constraint (3). As investment equals depreciation, not all resources that were used for investment go into R\&D.

Both quantities increase by the factor $A$ from one cycle to the other. The prediction about the timing of $\mathrm{R} \& \mathrm{D}$ is extreme and will empirically probably not hold. The more general prediction of the model is that $\mathrm{R} \& \mathrm{D}$ investment is larger, when returns to capital accumulation are low. ${ }^{15}$

\subsubsection{Long-run growth}

The model satisfies all of Kaldor's stylized facts (cf. e.g. Barro and Salai-Martin, 1995) which are relevant for the present model. (i) Per capita output grows at a constant rate: Output at some fixed point of a cycle $q$ can be written with (26) as $Y=A^{q} \hat{K}^{\alpha} L^{1-\alpha}$, where the aggregate production function (7) and the transformation (26) was used. As the labour force $L$ is constant and productivity-adjusted capital $\hat{K}$ is the same at some fixed point (take e.g. the capital stock on the $R \& D$ line) of any cycle, output per capita increases by $A$ from one cycle to the other. (ii) Physical capital per worker grows over time: This directly follows from $K / L=A^{q / \alpha} \hat{K} / L$ which uses the argument just made. (iii) The rate of return to capital is nearly constant: The interest rate was computed for the R\&D line in (29). As it is a function of the productivity-adjusted capital stock $\hat{K}$ only, it does not display any long-run trend. (iv) The ratio of physical capital to output is nearly constant: This stylized fact is the least obvious to see in the present model. Physical capital is measured as the value of all capital in an economy, deflated in an appropriate way. Here, the value of capital is given by its price $p_{K}$ per efficiency unit times the measure of the aggregate stock $K$. Using (8) and (13) yields $p_{K} K=B^{-q} p_{I} K$. Dividing by the value of output, $p_{C} Y$, yields

$$
\frac{B^{-q} p_{I} K}{p_{C} Y}=\frac{B^{-q} p_{I} A^{q / \alpha} \hat{K}}{p_{C} A^{q} \hat{K}^{\alpha} L^{1-\alpha}}=\frac{\hat{K}}{\hat{K}^{\alpha} L^{1-\alpha}},
$$

where we used $B^{-q} A^{q / \alpha}=A^{q}$. Hence, capital per output is constant. (v) The shares of labour and physical capital in national income are nearly constant: This directly follows from a Cobb-Douglas production function.

\footnotetext{
${ }^{15}$ In the discrete time version of the model mentioned in a footnote above, R\&D takes place all of the time. The discrete time version is not as tractable as the version presented here, however.
} 


\section{Conclusion}

The economy we have analyzed is characterized by short-run fluctuations and long-run growth. Both short-run fluctuations and long-run growth are caused by endogenous technology shocks.

Technology shocks are endogenous, i.e. the point in time when a shock occurs depends on decisions made by agents in this economy, as the economy offers two saving technologies. Households accumulate capital when returns to capital accumulation are sufficiently high. Capital accumulation implies decreasing capital returns and, at some point, households put their savings into $R \& D$ activities when capital returns are low. When $R \& D$ is successful, a new technology is available, i.e. a technology shock occurs, and returns to capital accumulation are high again.

This result follows from allowing households to be risk-averse. While capital accumulation and uncertain $R \& D$ have been studied in the literature, these results were so far not available as risk-averse households were not taken into consideration. The present paper has shown that including this feature considerably broadens the range of phenomenon to which models of creative destruction and long-run growth can be applied.

\section{References}

[1] Aghion, P. and Howitt, P., 1992, A Model of Growth through Creative Destruction. Econometrica 60: 323 - 351.

[2] Aghion, P. and Howitt, P., 1998, Endogenous Growth Theory. Cambridge, MA. MIT Press.

[3] Backus, D. K., Kehoe P. J., Kehoe, T. J., 1992, In Search of Scale Effects in Trade and Growth. Journal of Economic Theory 58: 377-409.

[4] Barro, R. J. and Sala-i-Martin, X., 1995, Economic Growth. New York, McGraw-Hill.

[5] Bental, B. and Peled, D., 1996, The Accumulation of Wealth and the Cyclical Generation of new Technologies: A Search Theoretic Approach. International Economic Review 37: 687 - 718.

[6] Dixit, A. K. and Olson, M., 2000. Does Voluntary Participation Undermine the Coase Theorem? Journal of Public Economics 76: 309 335. 
[7] Dixit, A. K. and Pindyck, R. S.,1994, Investment Under Uncertainty. Princeton University Press.

[8] Howitt, P., 1999, Steady Endogenous Growth with Population and R\&D Inputs Growing. Journal of Political Economy 107: 715 - 730.

[9] Howitt, P. and Aghion, P., 1998, Capital Accumulation and Innovation as Complementary Factors in Long-Run Growth. Journal of Economic Growth 3: 111 - 130.

[10] Jones, C. I., 1995, R\&D-Based Models of Economic Growth Journal of Political Economy 103: 759-84.

[11] Matsuyama, K., 1999, Growing through Cycles. Econometrica 67: 335 347.

[12] Segerstrom P. S., 1998, Endogenous Growth without Scale Effects. American Economic Review 88: 1290 - 1310.

[13] Segerstrom P. S., 2001, Intel Economics. Stockholm School of Economics, mimeo August 2001.

[14] Wälde, K., 1998. Poisson-Ramsey Economies: On the Endogeneity of Cycles in Economic Growth. Habilitationsschrift, Department of Economics, University of Dortmund.

[15] Wälde, K., 1999a, A Model of Creative Destruction with Undiversifiable Risk and Optimising Households. Economic Journal 109: C156 - C171

[16] Wälde, K., 1999b, Optimal Saving under Poisson Uncertainty. Journal of Economic Theory 87: 194 - 217.

[17] Wälde, K., 2001, The Economic Determinants of Technology Shocks in a Real Business Cycle Model. Forthcoming Journal of Economic Dynamics and Control.

[18] Young, A., 1998, Growth without Scale Effects. Journal of Political Economy 106: 41 - 63.

\section{Appendix}

available upon request 